\title{
Intercomparison of Methods for the Identification and Quantitation of Butyltin Species in Aqueous Solution
}

\section{NISTIR 4704}

\author{
PUBLICATIONS
}




\section{NATIONAL INSTITUTE OF STANDARDS \& TECHNOLOGY \\ Research Information Center \\ Gaithersburg MD 20899}

\section{DATE DUE}

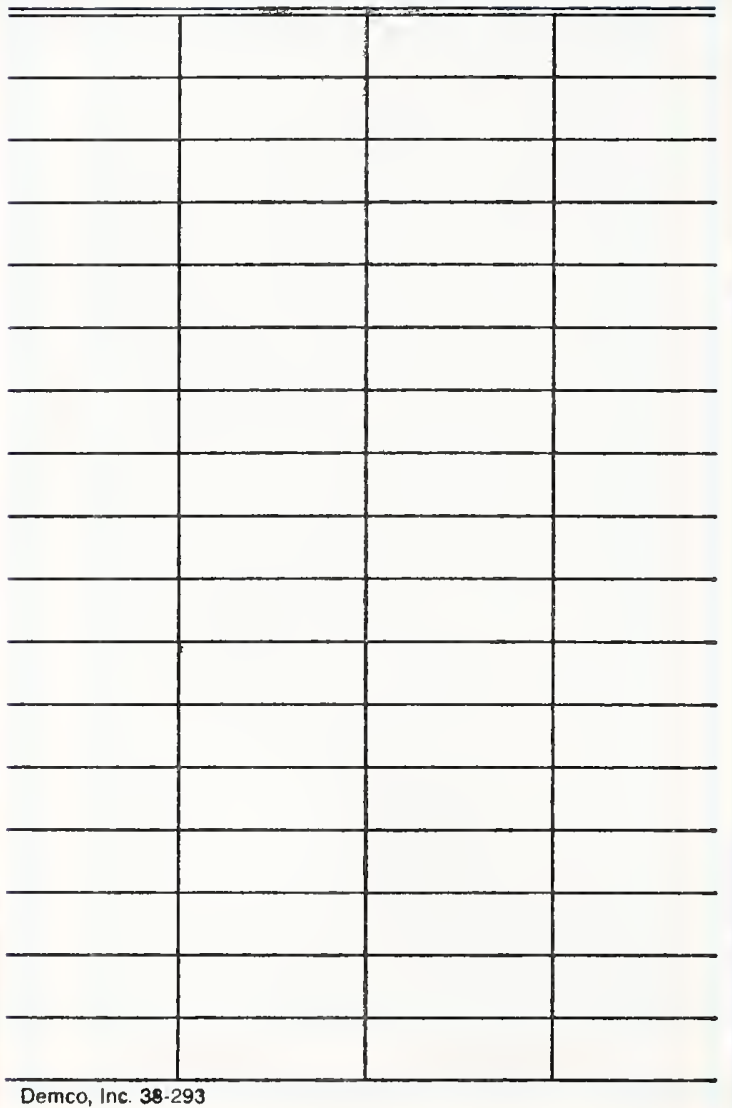




\section{Intercompaison of Methods for the Identification and Quantitation of Butyltin Species in Aqueous Solution}

W. R. Blair

F. E. Brinckman

R. Paule

U.S. DEPARTMENT OF COMMERCE Technology Administration National Institute of Standards and Technology

Materials Science and Engineering Laboratory

Polymers Division

Gaithersburg, MD 20899

Prepared for

David Taylor Research Center

Annapolis, MD 21402

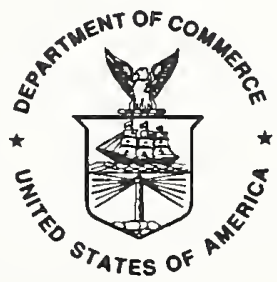

U.S. DEPARTMENT OF COMMERCE Rockwell A. Schnabel, Acting Secretary NATIONAL INSTITUTE OF STANDARDS AND TECHNOLOGY

John W. Lyons, Director 

Intercomparison of Methods for the Identification and

Quantitation of Butyltin Species in Aqueous Solution

W. R. Blair, F. E. Brinckman and R. Paule

National Institute of Standards and Technology

Materials Science and Engineering Laboratory

Polymers Division

Gaithersburg, Md 20899

Abstract

A comparison of measurement methods for the quantitation and speciation of butyltin species in water at low parts per trillion (ng/L) concentration levels has been completed with a specially prepared research sample. This report contains a summary of sample preparation techniques, analytical methods used in sample analysis and results of butyltin measurements made on the samples.

Keywords: antifouling coatings, tributyltin, organotin, methods intercomparison, speciation 

In 1984 an International Butyltin Measurement Methods Intercomparison (1) was initiated by the National Bureau of standards (now the National Institute of standards and Technology, NIST) with the distribution of a tributyltin research solution to laboratories worldwide. The research solution contained nominally $1 \mathrm{mg} / \mathrm{L}$ of tributyltin cation in aqueous solution. Analytical data submitted by the laboratories participating in the study demonstrated that any one of the seven different methods employed by the participants could yield accurate total tin values. The distribution of results did not indicate any bias in any specific method, but only laboratory to laboratory variation in the accuracy of total tin determination.

Over the past four to five years it has become accepted that total tin analysis is inadequate for evaluation of the environmental impact of organotins. Tributyltin has been identified as the organotin species responsible for a number of specific detrimental effects observed in the aquatic environment. Although effective as an antifouling additive to marine paints, tributyltin is highly toxic to a variety of nontarget marine organisms. For example, tributyltin at low parts per billion $(\mu \mathrm{g} / \mathrm{L})$ concentrations is acutely toxic to amphipod larvae (2), lobster larvae and zoeal shore crabs (3), sheepshead minnows (4), and mysid shrimp (5). At sub-parts per billion levels, tributyltin causes sublethal effects in zoeal mud crabs (6), mussel larvae (7), and copepods (8).

For accurate understanding of organotin effects on the environment, measurement methods providing quantitation and speciation of the actual butyltin compounds present in the aquatic environment are required. The measurement methodology must provide the sensitivity to detect butyltins at low parts per trillion ( $\mathrm{ng} / \mathrm{L}$ ) concentrations, the level at which environmental effects are observed.

In response to the need stated above, a variety of new methods (9-15) have been described for speciation of butyltin compounds in aquatic environments at low ng/L levels. These methods have general similarities. Butyltins present in a water sample are concentrated by organic solvent extraction or cryogenic trapping following derivatization by sodium borohydride (9, 13-15) or Grignard reaction (10-12). Separation of the butyltins is accomplished by chromatographic (9-12) or boiling point (13-15) methods, with detection provided by atomic absorption $(12,13,15)$, mass spectrometric (10), or flame photometric $(9,11,14)$ detectors.

Unfortunately, during the time that the new sensitive butyltin speciation methods were being developed and described in the scientific literature, no butyltin research standards became 
commercially available for use in evaluation or intercomparison of the new methods. With the sponsorship of the David Taylor Research Center, NIST prepared a new, sterile, multi-species, aqueous butyltin research solution and initiated a measurement methods intercomparison for high-sensitivity butyltin speciation methods.

\subsection{Experimental}

The multi-species butyltin research sample was produced by the use of a chromatographic generator column technique (described in detail in reference 1) in which one set of columns produced a saturated aqueous dibutyltin solution and a second independent set of columns produced a saturated aqueous tributyltin solution. The flow streams of the two columns were collected in individual reservoirs and combined in a single 25 liter polycarbonate vessel to produce a homogenous master reference solution. To prevent the possibility of bacterial degradation or redistribution of the butyltin species in the research solution, all components of the chromatographic system were sterilized before use. The glass generator columns, the deionized feed water and glass or polycarbonate reservoirs were autoclaved, as were the individual $125 \mathrm{~mL}$ sample bottles. Chromatographic pumps that could not be autoclaved had their liquid flow paths sterilized by pumping aqueous nitric acid solutions, followed by sterile deionized water.

The multi-species butyltin research solution contained diand tributyltin with a combined concentration, expressed as the cation; of approximately $2.2 \mathrm{mg} / \mathrm{L}$. This concentration level was too high to challenge the detection capabilities of the highsensitivity butyltin speciations methods. A dilution of the research solution was made at NIST prior to dispensing into 1.5 $\mathrm{mL}$ vials to bring the butyltin concentration to a low $\mu \mathrm{g} / \mathrm{L}$ level. Concern for stability of the research solution during shipping and storage while awaiting analysis prevented dilution to low ng/L levels at NIST. Recipients of the sample were required to make a final 1:1000 dilution of the research solution just prior to analysis, bringing the butyltin concentration to low ng/L levels. (See Appendix I for a copy of the cover letter and analysis instructions that accompanied the research material.)

\subsection{Results and Discussion}

One of the major unknowns concerning this butyltin speciation methods intercomparison was the stability of the research material. Past experience with aqueous butyltin solutions provided confidence that master solutions prepared at approximately $1 \mathrm{mg} / \mathrm{L}$ levels were stable for several years. However, the stability of $\mu \mathrm{g} / \mathrm{L}$ and $\mathrm{ng} / \mathrm{L}$ solutions was unknown but 
suspected to be poor due to butyltin adsorption on container walls. In reviewing the values for tributyltin concentration determined at NIST during the course of this study, it is clear that the research material suffered a significant loss of tributyltin concentration. When freshly prepared at NIST, the bulk research material contained (by Method F below) tributyltin at a concentration of $13 \mathrm{ng} / \mathrm{L}$, with a standard deviation of 2.7 $\mathrm{ng} / \mathrm{I}$ and a relative standard deviation of $21 \%$. When the tributyltin concentration of bulk and vialed samples was determined 15 months later, the tributyltin concentration had decreased. The bulk solution had a tributyltin concentration of $8.9 \mathrm{ng} / \mathrm{I}$, with a standard deviation of $2.0 \mathrm{ng} / \mathrm{L}$ and the vialed samples contained $0.5 \mathrm{ng} / \mathrm{L}$, with a standard deviation of 0.05 ng/L. Concentration loss of tributyltin in the bulk solution was $31.5 \%$, while the vialed sample lost $96.1 \%$ of the original tributyltin concentration. Tributyltin adsorption to the container walls is presumed to be the primary cause of concentration loss in the research solution, not degradation. The $1.5 \mathrm{~mL}$ sample vials, which showed the most dramatic concentration loss, have a much larger surface area to volume ratio than the bulk solution storage container.

Nine laboratories received butyltin research sample sets consisting of ten $1.5 \mathrm{~mL}$ vials containing $1.0 \mathrm{~mL}$ of research solution. Seven laboratories have returned analytical data of their butyltin speciation measurements. Tributyltin speciation data is presented in Table 1 and Figure 1. Table 1 lists all the raw data for the replicate analyses performed on the sample sets, ordered by increasing value. It is apparent by comparing the tributyltin concentrations measured to the dates at which analyses were performed that no elapsed time related trend is apparent. Figure 1 shows a graphical representation of the mean tributyltin concentration values for each vial set measured by analytical methods $A$ through $F$.

The interlaboratory data, which were obtained over a six month period, showed no evidence of sample degradation during the time period in which the round robin participants were making speciation measurements. It would appear that the interlaboratory measurements were made over a sufficiently short period to not be affected. The interlaboratory mean tributyltin concentration was found to be $6.2 \mathrm{ng} / \mathrm{L}$, with a standard error (standard deviation of the mean) of $0.8 \mu \mathrm{g} / \mathrm{L}$. The pooled within laboratory standard deviation was $1.3 \mathrm{ng} / \mathrm{L}$ and the between laboratory standard deviation was $2.1 \mathrm{ng} / \mathrm{L}$. This results in ASTM repeatability and reproducibility limits of $3.6 \mathrm{ng} / \mathrm{L}$ and 6.9 $\mathrm{ng} / \mathrm{L}$, respectively. The ASTM terms used above are defined in the book of ASTM standards, volume 14.02, (1991), standard E 456-90a.

An apparent contradiction has been created in the preceding paragraphs. We point out that the tributyltin research material has lost significant concentration strength over a 15 month 
period, but then later, state that during the six month time period when round robin measurements were being made, the data received from the round robin laboratories showed no evidence of tributyltin concentration loss in the sample. This contradiction is the result of the low tributyltin concentration $(0.5 \mathrm{ng} / \mathrm{L})$ found in the vialed samples when final measurements of tributyltin concentration were made at NIST, seven months after the last round robin measurements were made and 15 months from the time that the research solution was transferred into vials.

We feel the final NIST measurements are reliable and accurate. A five point instrument calibration was employed, incorporating calibration points at $0.2,0.6,1.8,3.7$ and 7.3 ng $\backslash \mathrm{L}$ tributyltin concentrations. The final concentration measured for the vialed samples, $0.5 \mathrm{ng} \backslash \mathrm{L}$, although low, was within the range of the calibration points and had a relative standard deviation of $11.4 \%$, a deviation considered acceptable in making tributyltin measurements at this concentration level. A plot of the calibration curve is shown in Figure 2 .

Perhaps the best way to resolve this point would be to solicit volunteers from among the round robin laboratories to remeasure the tributyltin concentration of vialed samples in storage at NIST. However, due to the length of time required to solicit volunteers to perform measurements and return results, this course of action will not be pursued.

A brief summary of the various methods employed for the analysis of the sample vials is listed below. The methods have been arbitrarily identified as Method A, Method B, and so on. Each laboratory used a method of its own choice for analysis of the butyltin research material, with two laboratories independently choosing to use method $B$.

Method A: Hydride formation with sodium borohydride, purge and trap in liquid nitrogen cooled trap, boiling point elution, followed by atomic absorption detection of tin.

Method B: N-hexane/tropolone extraction, followed by derivitization with $n$-hexylmagnesium bromide. The sample is then eluted through an activated florisil column, reduced in volume and butyltins determined by gas chromatography with flame photometric detection (GC-FPD).

Method C: Hydride formation with sodium borohydride, extraction with petroleum ether, reduce volume and determine butyltins by GC-FPD.

Method D: Methylene chloride/tropolone extraction, evaporate to dryness and take up in benzene and derivatize with pentylmagnesium bromide. Derivitized solution washed with benxene/sulfuric acid followed by distilled water. Volume 
reduced and benzene solution taken up in hexane, eluted through a silica gel column with hexane and again reduced in volume.

Analysis for butyltins by gas chromatography-mass spectrometry (GC-MS).

Method E: Benzene/tropolone/HCl extraction, reduce volume and derivitize with propylmagnesium bromide. Extract with hexane, wash with distilled water and reduce volume. Elute through a silica column, reduce volume and determine butyltins by GC-FPD.

Method F: Hydride formation with sodium borohydride simultaneous with extraction by methylene chloride. Reduce volume and determine butyltins by GC-FPD.

\subsection{Summary and Conclusions}

It is fair to conclude that any one of the six different methods employed by the participants in this study can yield accurate butyltin speciation measurements at low $\mathrm{ng} / \mathrm{L}$ concentration levels. No bias is seen in any specific analytical method.

The research sample used in this study did not possess good long term stability. Poor stability was a major concern in trying to generate a tributyltin research sample with a very dilute concentration in the low $\mu \mathrm{g} / \mathrm{L}$ range. Unfortunately, our concerns about long term stability of the solution concentration proved to be true. The use of a complexing or chelating compound in the research solution may improve stability, although our laboratory has not investigated this prospect for dilute tributyltin solutions.

As a result of conducting this interlaboratory methods comparison, several important features have been identified that would aid in the smooth conduct of similar studies in the future. We recommend the inclusion of the following items in any interlaboratory methods comparisons:

** State clearly what method of methods may be used to generate data for the intercomparison. Request a detailed description of the method used by each participant.

** Request that sample recipients inform you when they receive their sample and indicate its condition; i.e., good condition, leaking, broken.

* Give precise instructions as to how the sample should be handled upon receipt; i.e., stored in the dark, refrigerated, analyzed as received or diluted. 
**' Give precise instructions concerning how data are to be reported. Define a replicate sample analysis, state how many replicate analyses are required and indicate that raw data or averaged results are required. State clearly the units to use in reporting results.

** State a time limit for the return of analytical data.

\subsection{Acknowledgments}

We would like to thank all the laboratories that responded to our inquiry as to interest in this butyltin measurement methods intercomparison. Special thanks go to the laboratories that expended time and resources to make butyltin speciation measurements of the research sample. Acknowledgment is made to Mr. Paul Schatzberg at the David Taylor Research Center, Annapolis, Maryland for his sponsorship of this effort, encouraging and helpful suggestions while the work was in progress and patience in awaiting the completion of the study.

\subsection{References}

1. Blair, W.R., Olson, G.J., and Brinckman, F.E., NBSIR 863321 (prepared for office of Naval Research) February, 1986, $56 \mathrm{pp}$.

2. Laughlin, R. B., Nordlund, K., Linden, O., Mar. Environ. Res., 1984, 12, 243-271.

3. Laughlin, R. B., French, W. J., Bull. Environ. Contam. Toxicol., 1980, 25, 802-809.

4. Ward, G. S., Cramm, G. C., Parrish, P. R., Trachman, H., Slesinger, A., in "Aquatic Toxicology and Hazard Assessment: Fourth Conference", Branson, D. R., Dickson, K. L., Eds., American Society for Testing and Materials: Philadelphia, 1981, ASTM STP 737, pp 183-200.

5. Seligman, P. F., "Fate and Effects of Organotin Antifouling Leachates in the Marine Environment" progress report prepared for Energy Research and Development office, David W. Taylor Ship Research and Development Center, Bethesda, MD, 1984, pp 1-47.

6. Laughlin, R. B., French, W., Guard, H. E., Water, Air, Soil, Pollut., 1983, 20, 69-79.

7. Beaumont, A. R., Budd, M. D., Pollut. Bull., 1984, 15, 402405 .

8. U'Ren, S. C., Mar. Pollut. Bull., 1983, 14, 303-306. 
9. Matthias, C. L., Olson, G. J., Brinckman, F. E., and

Bellama, J. M., Environ. Sci. Technol., 1986, 20, 609-615.

10. Mueller, M. D., Fresenius Z. Anal. Chem., 1984, 317, 32-36.

11. Maguire, R. J., Chau, Y. K., Bengert, G. A., Hale, E. J., Wong, P. T. S., and Kramer, O., Environ. Sci. Technol., $1982,16,698-702$.

12. Maguire, R. J., Tkacz, R. J., J. Chromatogr., 1983, 268, 99101.

13. Valkirs, A. O., Seligman, P. F., stang, P. M., Homer, V., Lieberman, S. H., Vafa, G., and Dooley, C. A., Mar. Pollut. Bull. 1986, 17, 319-324.

14. Braman, R. S., and Tompkins, M. A., Anal. Chem., 1979, 51, 12-19.

15. Hodge, V. F., Seidel, S. L., and Goldberg, E. D., Anal. Chem., 1979, 1256-1259. 
TABLE 1

ORDERED RESULTS Of TRIBUTYLTIN ANALYSIS

Values are for tributlytin cation, expressed in $\mathrm{ng} / \mathrm{L}$

Vial

number

$\# 2$

Vial set Number

Method

A

\#3

\#4

\#5

\#6

\#8

\#9

D

F

B

C

B

1

1.8

5.5

3. 4

6.7

7

9.2

2

2.0

5.5

5.4

6.3

$<6$

8.5

3

2.3

3.9

4. 1

5.6

8

$8 \cdot 3$

4

2.6

4. 4

5.1

7.9

8

7.5

5

3.3

$4 \cdot 5$

$8 \cdot 5$

5. 4

7

10

6

2.7

3.9

7.3

7.3

6.3

6.9

7

7

8

2. 7

4. 4

6.2

12

9.7

9

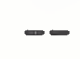

2.6

$-$

2.6

$-$

7. 3

12

9.8

10

3.9

4.5

$-$

6.5

7

6

10

6

8.4

MEAN $\mathrm{X}$

2.8

$4 \cdot 2$

$5 \cdot 7$

6.6

7.2

7.9

9.0

STD. DEV . 0.7

1.0

1.8

0.8

0.6

$2 \cdot 3$

0.9

Analysis

Date

$9 / 6 / 89$

$8 / 9 / 89$

$3 / 15 / 90$

$2 / 16 / 90$

$9 / 5 / 89$

$9 / 13 / 89$

$8 / 11 / 89$ 


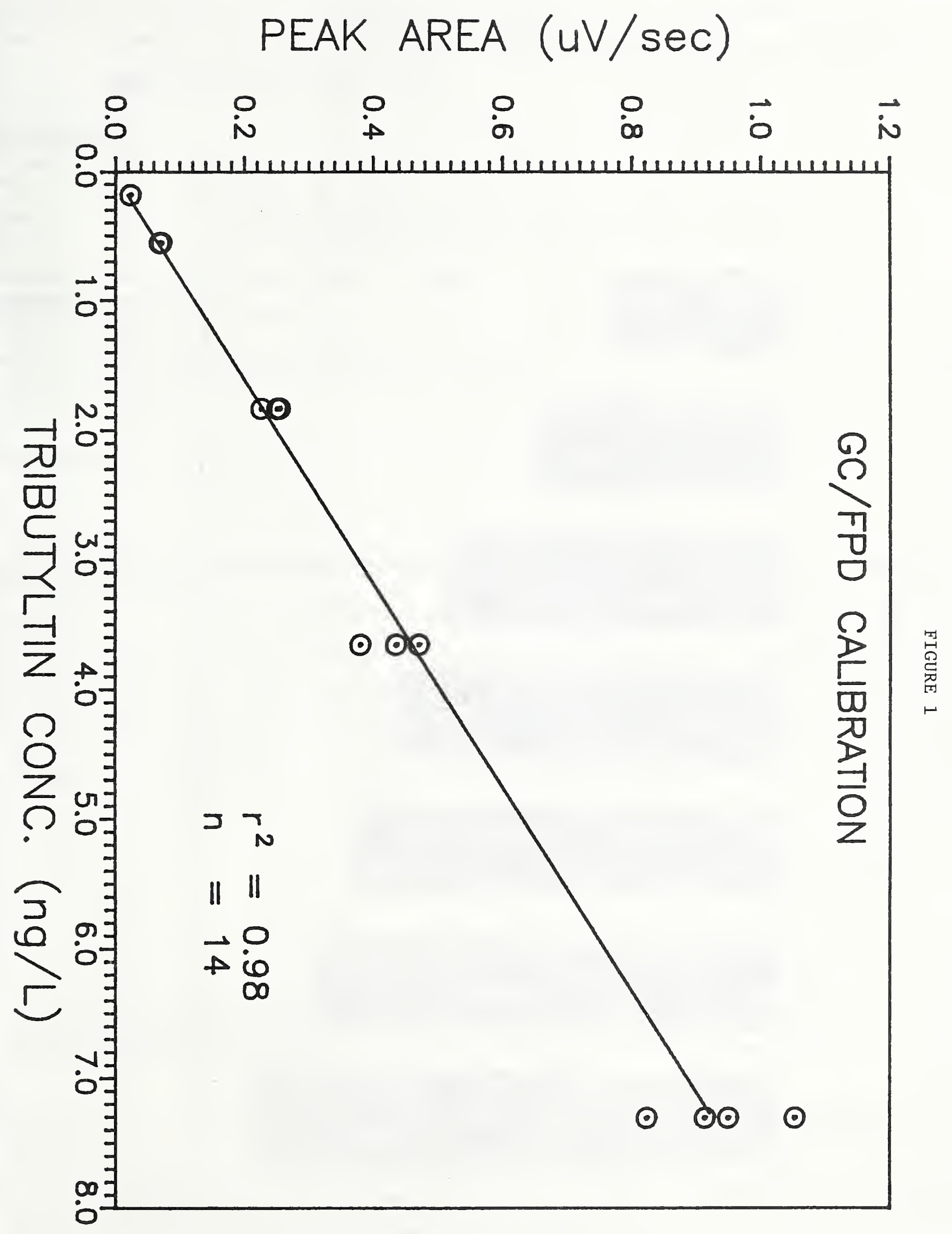


TRIBUTYLTIN CONC. (ng/L)

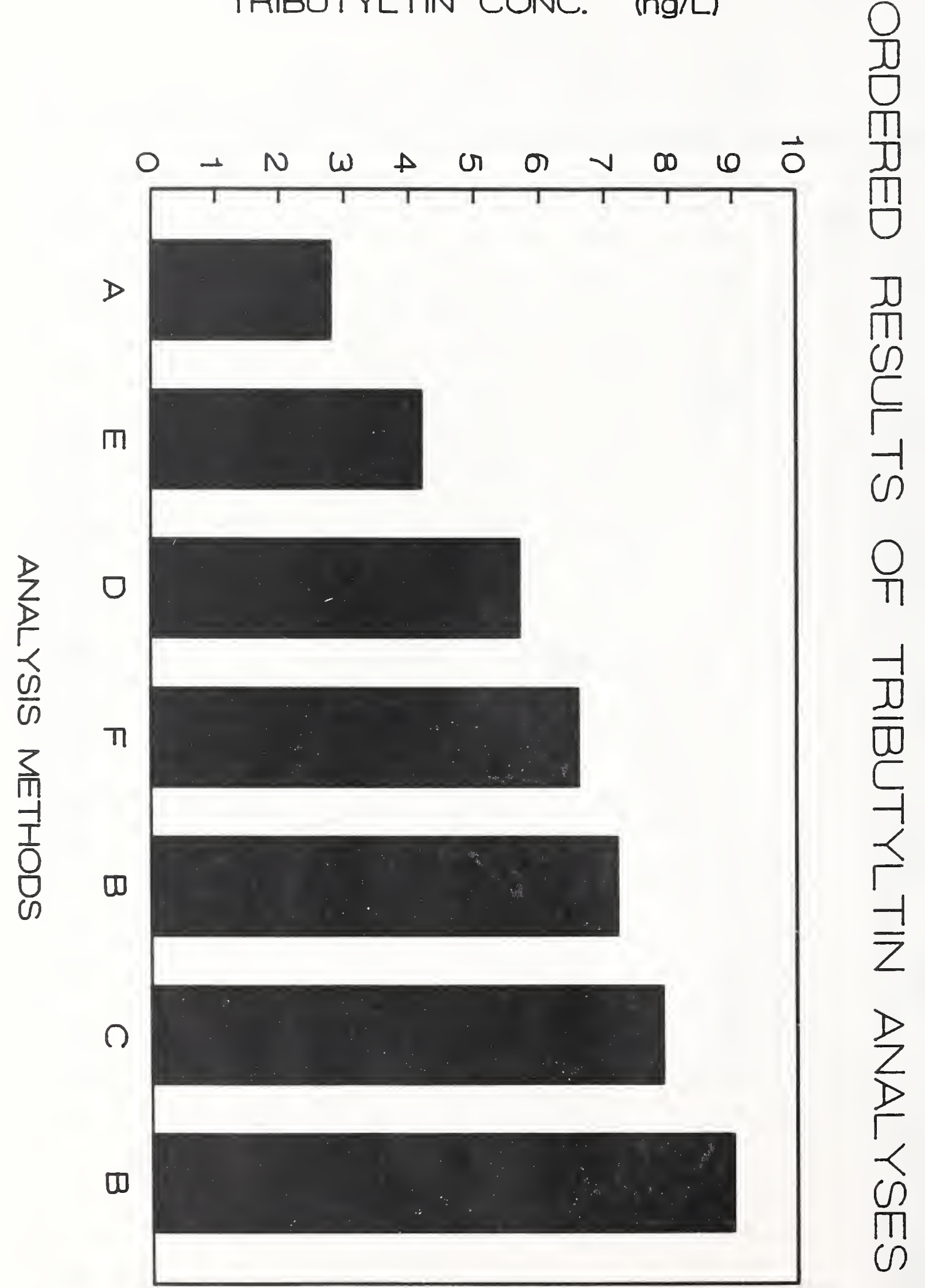


(REV. 3-80)
U.S. DEPARTMENT OF COMMERCE NATIONAL INSTITUTE OF STANDARDS AND TECHNOLOGY

\section{BIBLIOGRAPHIC DATA SHEET}

1. PUBUCATION ON AEPOAT MUMEEA

NISTIR 4704

2. PERFOAMINO OAGAMIZATION REPOAT NUMBER

3. PUEUCATION DATE

JANUARY 1992

\section{TITE AND SUDTIILE}

Intercomparison of Methods for the Identification and Quantitation of Butyltin Species in Aqueous Solution

5. AUTHOA(S)

W. R. Blalr, F. E. Brinckman and R. Paule

6. PEAFOAMIHO ORQAMIZATIOH (IF JOINT OA OTHEA THAN NIST, SEE INSTAUCTIONS)

U.S. DEPARTMENT OF COMMERCE

MATIONAL INSTITUTE OF STANDAROS ANO TECHMOLOOY

QATHERSEURG, MO 20690

\section{CONTRACT/ORANT MUMBER}

2. TYPE OF REPOAT AMD PERIOD COVERED

2. SPOHSORIHO OAGAMIZATIOM MAME ANO COMPLETE ADOAESS (STAEET, CTT, STATE, ZPF)

David Taylor Research Center

Annapolis, MD 21402

10. SUPPLEMENTAAYMOTES

11. ABSTRACT (A 2OO-WOAD OR LESS FACTUAL SUMMAAY OF MOST SIONIFICANT IMFOALATION. IF DOCUMEMT INCLUDES A SIOMIFICANT CIBUOORAPHY OA UTERATURE SUAVEV, MENTION IT HERE)

A comparison of measurement methods for the quantitation and speciation of butyltin species In water at low parts per trillion (ng/L) levels have been completed with a speclally prepared research sample. This report contains a summary of sample preparation techniques, analytical methods used in sample analysis and results of butyltin measurements made on the samples.

12. KEY WOADS (6 TO 12 ENTAIES; NLPHABETICAL OADER; CAPITALZE ONLY PROPER MAMES; AND SEPARATE KEY WOADS EY SEMICOLONS) antifouling coatings; International Round Robin; methods intercomparison; organotin; speciation; tributyltin

13. AVALABUTY

$\mathrm{X}$

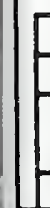

\section{UHUMTRED}

FON OFFICLAL OISTRIBUTIOH. DO NOT REEASE TO MATIOMAL TECHHICAL INFORMATION SERVCE (NTIS).

ORDER FROM SUPERINTENDENT OF DOCUMENTS, U.S. OOVERMMENT PAINTINO OFFICE, WASHIMOTOH, OC 20402 .

ORDER FROM MATIOKAL TECHNICAL IMFOAMATION SERVCE PTIS), SPRIMOFIELD, VA 22161.
14. NUMBEA OF PRINTEO PAOES

$$
14
$$

15. PAICE A02 


